recipients of cell lines can be confident in (and satisfied with) the material received, which is, after all, the point of the exercise.

Culture collections should provide the gold standard in authentication and are in the best position to cross-reference all the techniques used. Ideally, such an approach should be made by culture collections on a collaborative basis and lead to availability of identical material in cell banks as recommended by the World Health Organisation ${ }^{3}$.

In conclusion, the environment within which most culture collections operate demands that authentication procedures are not only accurate but also practicable. Although acknowledging that exhaustive characterization is a worthy goal, it would severely limit the range of material available. Most researchers would not be able to afford the necessary fees to establish such a high level of quality assurance. Hold on to your microscopes for cytogenetics by all means, but remember that you will need to find the time and money to use them.

Glyn N. Stacey

Bryan J. Bolton

Alan Doyle

European Collection of Animal Cell Cultures,

Public Health Laboratory Service,

Centre for Applied Microbiology \&

Research

Porton Down, Salisbury,

Wiltshire SP4 OJG, UK

1. Stacey, G. N., Bolton, B. J. \& Doyle. A. Nature 357,
$261-262$ (1992).
2. Dewar, A. E. et al. Biologics 18, $289-294$ (1990).
3. Worid Heaith Organisation Acceptability of Cell
Substrates for Production of Biologicals Tech. Rep. Ser.
747WHO (Geneva, 1987).

\section{Winged Late Devonian seeds}

SIR - The evolution of the seed in 'ancestral' gymnosperm plants represented a major adaptive breakthrough in terms of pollination, protection and propagule dispersal ${ }^{1}$. Seeds from Devonian gymnosperms show remarkably little variability in the structure and presumed function of the integument, $a$

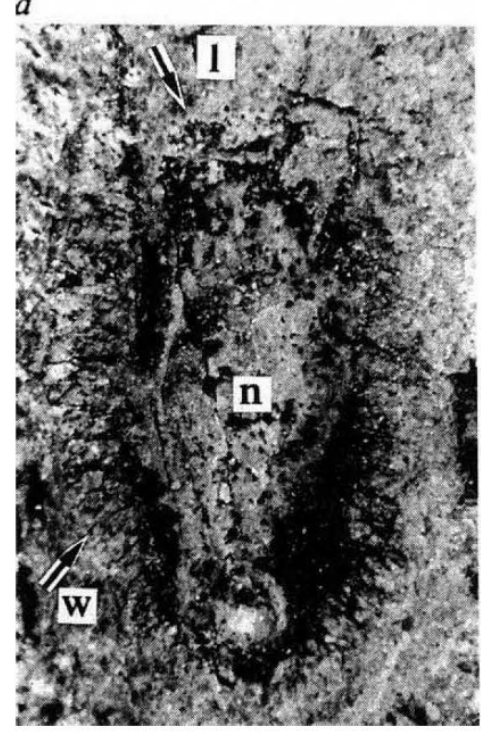

a, Compression of seed showing evidence of two winged integument lobes; n, nucellar region; I, lagenostome; w, winged integument lobe. Magnification, 15×. b. Simplified diagram of seed compression surface with winged integument lobes. The dotted outline indicates the position of another integument lobe orientated perpendicularly to the plane of compression.

which consisted of simple narrow lobes ${ }^{2-5}$. Late Devonian seeds with a specialized 'winged' integument discovered in central Germany ${ }^{6}$ represent the earliest evidence of an integument adapted for wind dispersal in seed plants.

The new fossil seeds have three main components (see $a$ in figure) as inter- preted from critical observation and sections of fossils in the sediment. These are (1) the nucellar region (n); (2) the lagenostome (1) (a specialized funnel-shaped opening to allow entry of pollen); (3) winged integument lobes (w) consisting of inner, longitudinally aligned organic material, and a broad

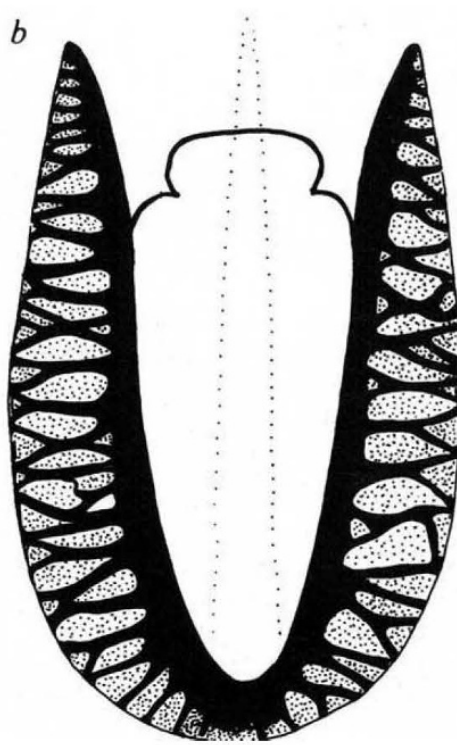

$1 \mathrm{~mm}$ the 'ancestral' integument that characterizes all other unequivocal Devonian seeds. Earlier data suggested ${ }^{7}$ a major diversification of seed plants by the Late Tournaisian that included forms with winged seeds; this indicated adaptive radiation on a large scale, with implications of ecologically diverse strategies of pollination, dispersal and colonization $^{8.9}$.

The winged integument is interpreted as being an adaptation to aid dispersal. Enhancing the aerodynamic properties of the Devonian seed would boost the dispersal potential of the propagule by increasing flotation in the air and saltation along the ground. Besides improving dispersal, a winged integument also increases the probability of adherence to a substrate suitable for continued growth of the seedling by optimizing the shape and surface area of the seed. This viewpoint differs from previous interpretations of the functional adaptation of the integument, which have stressed the importance of protection ${ }^{1}$ and optimization of pollination ${ }^{10}$.

A range of ecological strategies was developed by a rapidly diversifying group of seed plants well before the Late Tournaisian. This diversification is now documented in the form of a highly divergent, winged integument morphology before the end of the Devonian. It is, therefore, premature to consider integument function solely in terms of pollination and/or protection. Selective advantages among Devonian seed plants involved specialized dispersal mechanisms and these are now documented in the form of winged integument lobes.

\section{N. P. Rowe}

Department of Geology,

Royal Holloway and Bedford New College, University of London,

Egham Hill,

Surrey TW2O OEX, UK

1. Rothwell, G. W. \& Scheckler, S. E. in Origin and Evolution of Gymnosperms (ed. Beck, C. B.) 85-134 (Columbia University Press, New York, 1988)

2. Pettitt, J. M. \& Beck, C. B. Contr. Mus. Paleont. Univ. Mich. 22, 139-154 (1968)

3. Matten, L. C., Lacey, W. S. \& Lucas, R. C. Bot. J. Linn. Soc. Lond. 8, 249-278 (1980).

4. Gillespie, W. H., Rothwell, G. W. \& Scheckler, S. E Nature 293, 462-464 (1981).

5. Fairon-Demaret, M. \& Scheckler, S. E. Bull. Inst. R Sci. nat. Belg. 57, 183-199 (1987).

6. Higgs, K. \& Streel, M. Cour. Forsch. Senckenberg $6 \mathbf{7}$ 157-179 (1984).

7. Long. A. G. Trans. R. Soc. Edinb. 69, 267-293 (1975).

8. Dimichele, W. A., Davis, J. I. \& Olmstead. R. G. Taxon 38, 1-11 (1989).

9. Galtier, J. \& Rowe, N. P. Nature 340, 225-227 (1989). 10. Niklas, K. J. Bot. Rev. 51, 328-386 (1985)

\section{Scientific Correspondence}

outer region with conspicuous transverse 'fibres'. Up to four winged lobes have been observed in some seeds, with additional lobes visible as one or two longitudinal grooves perpendicular to the plane of compression (dashed outline in $b$ ).

This highly derived integument morphology is considerably different from
Scientific Correspondence is intended to provide a forum in which readers may raise points of a scientific character. They need not arise out of anything published in Nature. In any case, priority will be given to letters of fewer than 500 words and five references.

NATURE · VOL 359 • 22 OCTOBER 1992 